\title{
RANCANG BANGUN SMART URINOIR UNTUK MENDETEKSI STATUS DEHIDRASI BERBASIS IMAGE PROCESSING DENGAN METODE JARINGAN SYARAF TIRUAN PERCEPTRON
}

\author{
Irfanuddin Mudzaki, Riza Alfita, Miftachul Ulum \\ Program Studi Teknik Elektro, Fakultas Teknik Universitas Trunojoyo Madura \\ irfanuddinmudzaki@gmail.com, riza.alfita@trunojoyo.ac.id, miftachul.ulum@trunojoyo.ac.id
}

\begin{abstract}
Abstrak
Dehidrasi merupakan suatu kondisi dimana tubuh sedang kekurangan cairan .Dehidrasi sangatlah berbahaya bagi tubuh manusia. Dengan mengetahui status dehidrasi maka pencegahan terhadap berbagai penyakit juga dapat diketahui lebih awal. Rancang bangun smart urinoir ini bertujuan untuk mengetahui status tingkat dehidrasi seseorang. Alat ini dirancang portable karena menggunakan rashberry pi untuk pengolahan sistem khususnya pada image processing. Dengan menggunakan sensor pir sebagai pendeteksi keberadaan seseorang maka kamera Logitech C270 akan mengambil sebuah gambar urin dan dapat diketahui nilai rata-rata HSV nya. Nilai rata - rata HSV yang didapatkan akan diatur pada sebuah program training melalui software Python untuk mendapatkan nilai $\mathrm{W}$ dan bias. Nilai $\mathrm{W}$ dan bias ini yang akan dimasukkan dalam sebuah metode jaringan syaraf tiruan pada software python di dalam sebuah rashberry pi untuk mencari nilai $\mathrm{U}$ dan Y sehingga diperoleh hasil klasifikasi tingkat dehidrasi berat, dehidrasi sedang atau dehidrasi ringan. Penelitian dilakukan di Laboratorium Elektronika dengan mengambil 25 sampel urin. Dari hasil penelitian dengan menggunakan 25 sampel uji diperoleh presentase tingkat keberhasilan sebesar $95 \%$ dengan pembagian dehidrasi yakni 41 tidak dehidrasi, 15 dehidrasi ringan, 1 dehidrasi berat, dan 3 tidak sesuai.
\end{abstract}

Kata kunci: Smart urinoir, Sensor pir, Jaringan syaraf tiruan

\section{PENDAHULUAN}

Organ atau alat ekskresi pada manusia memiliki fungsi yang sangat penting yaitu untuk membuang zat-zat sisa hasil metabolisme dalam tubuh. Zat sisa ini harus segera dikeluarkan dari tubuh manusia karena terdapat racun dan bisa menyebabkan beberapa penyakit. Jika pemasukan air untuk tubuh lebih rendah daripada air yang dikeluarkan oleh tubuh, maka akan menyebabkan penyakit kekurangan cairan. Gangguan keseimbangan antara pemasukan dan pengeluaran air inilah yang menyebabkan dehidrasi [1] .Centers for Disease Control and Preventation Amerika menyebutkan bahwa sekitar $45 \%$ penyakit gagal ginjal yang diderita oleh penduduk di usia 20 tahun ke atas disebabkan oleh dehidrasi. Dehidrasi dibagi menjadi 3 macam yaitu dehidrasi berat, dehidrasi ringan, dan dehidrasi ringan. Dehidrasi ringan yang berkelanjutan dapat mengakibatkan tidak berfungsinya lagi fungsi ginjal dalam tubuh manusia. Tidak semua orang bisa membedakan status tingkat dehidrasi mereka dengan mudah. Untuk membedakan tingkat dehidrasi biasanya dilakukan dengan mencocokkan warna urine dengan kertas aturan warna klasifikasi dehidrasi. Hal ini tentunya kurang efisien dan banyak orang lebih memilih untuk menghiraukan tingkat dehidrasi mereka.

Pada penelitian ini akan dibuat sebuah smart urinoir untuk mengetahui tingkat dehidrasi seseorang dengan lebih cepat tanpa harus memakai kertas warna. Alat ini mengunakan sensor pir untuk mendeteksi keberadaan seseorang dan kamera sebagai media untuk klasifikasi tingkat dehidrasi yang diolah pada
Hasil klasifikasi dehidrasi akan ditampilkan pada LCD sehingga pengguna dapat dengan mudah mengetahui status dehidrasi mereka secara realtime.

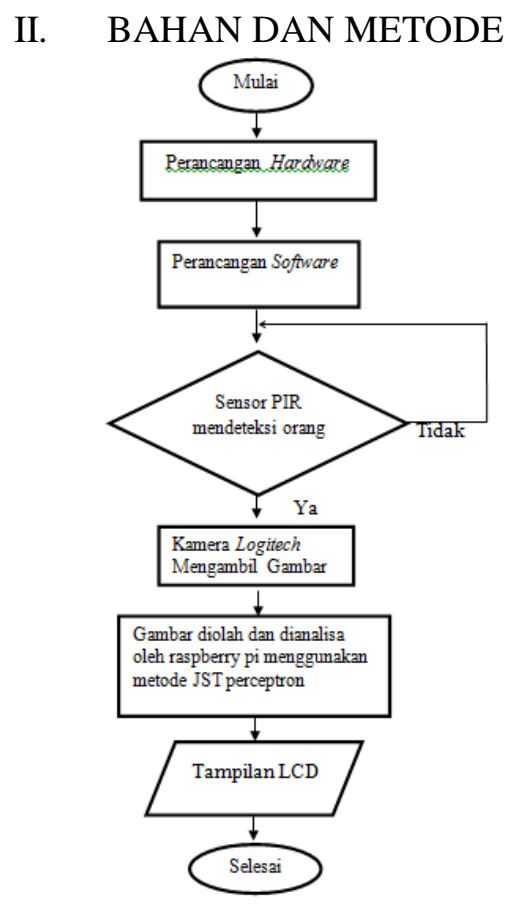

Gambar 1. Perancangan

Irfanuddin: Rancang Bangun Smart Urinoir ...

E-ISSN 2715-6427 
A. Perancangan Hardware

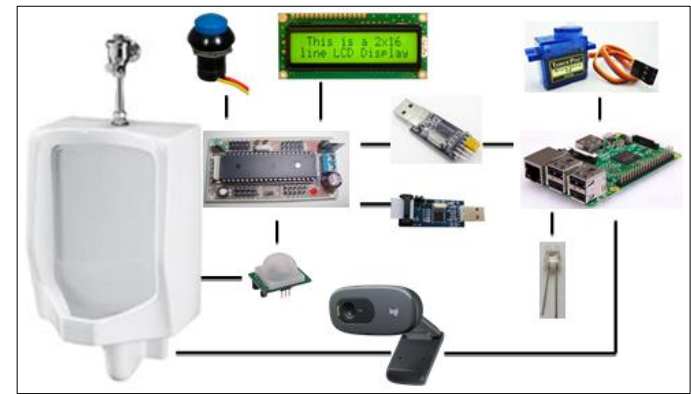

Gambar 2. Blok diagram koneksi hardware

Koneksi hardware pada gambar 2.1 dapat dijelaskan bahwa komponen yang digunakan terdiri dari minimum system dengan IC ATmega32, kamera Logitech c270, komunikasi serial berupa usb ttl, downloader, raspberry pi, push button, lcd 1602, lampu led dan sensor PIR. Proses yang terjadi pada perangkat hardware ini ialah sebuah urionir yang terbuat dari akrilik akan menampung cairan berupa urin. Sensor PIR yang dihubungkan menggunakan kabel jumper ke minimum system dengan IC ATmega32 inilah yang akan menjalankan proses pertama kali. Sensor PIR membutuhkan tegangan sebesar $5 \mathrm{~V}$ untuk dapat mendeteksi keberadaan seseoran di depan urinoir tersebut. Informasi sensor berupa seberapa besar tegangan output yang dihasilkan akan diproses menggunakan rashbery pi. Setelah melalui tahap pengolahan menggunakan metode jaringan syaraf tiruan perceptron, minimum system akan mengirimkan sebuah perintah untuk menampilkan sebuah informasi pada LCD 1602 berupa text.

B. Skematik Hardware

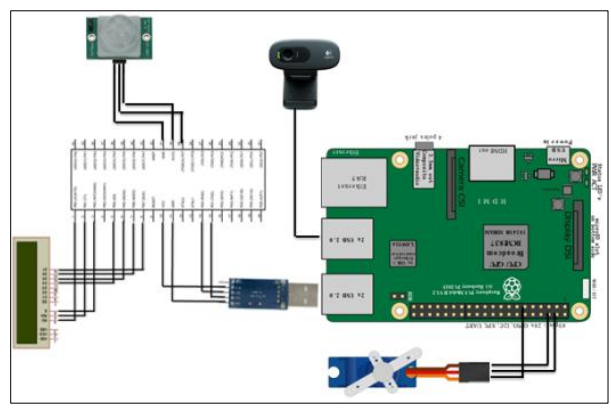

Gambar 3 Skematik Hardware

Berdasarkan gambar 2 diketahhui bahwa Atmega32 sebagai chip rangkaian elektronika memiliki 32 input output yang dihubungkan dengan berbagai komponen lainnya yaitu LCD 1602, sensor PIR dan USB to TTL. Pada skematik wearing diatas port dari LCD dihubungkan dengan PORT B, VCC dan GROUND pada ATmega32. Pada USB serial port dihubungkan dengan VCC $5 \mathrm{~V}$, GROUND, RX, TX, VCC 3,3V GROUND pada ATmega32. Sedangkan untuk sensor PIR port disambungkan pada

Irfanuddin: Rancang Bangun Smart Urinoir ...
PORT VCC, GROUND, dan PORT read ADC A0 pada ATmega32.

Untuk motor servo PORT VCC dan GROUND dihubungkan dengan PORT 5V dan GROUND dari Raspberry PI. Sedangkan PORT PWM dihubungkan dengan PORT 11 pada raspberry pi yang merupakan PIN GPIO 17. Kamera logitech C270 dihubungkan dengan PORT USB pada Raspberry Pi. Pin VCC pada LED dihubungkan dengan Raspberry $\mathrm{Pi}$ dan pin GROUND pada LED dihubungkan dengan GROUND pada Raspberry Pi.

\section{Perancangan Software}

Perancangan software terdiri dari beberapa software yang akan digunakan untuk pembuatan smart urinoir yaitu CvAvr, Pyhton, dan Extreme Burner. CvAvr digunakan untuk pembacaan nilai digital dari sensor PIR, menampilkan karakter berupa text pada LCD, komunikasi serial (USART) sebagai transmitter dan receive. Python digunakan untuk menggerakkan motor servo $90^{\circ}$, menampilkan nilai mean dari masing - masing $\mathrm{H}, \mathrm{S}$, dan $\mathrm{V}$, melakukan proses metode JST perceptron, menampilkan nilai $\mathrm{U}$ dan $\mathrm{Y}$, menampilkan status dehidrasi dari perhitungan metode JST, komunikasi serial (USART) sebagai transmitter ataupun receiver, menghidupkan $\mathrm{LED}$

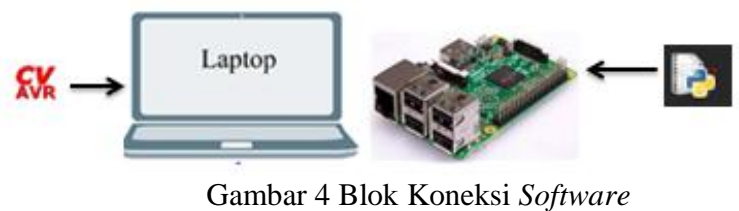

D. Proses Pembacaan Sensor PIR

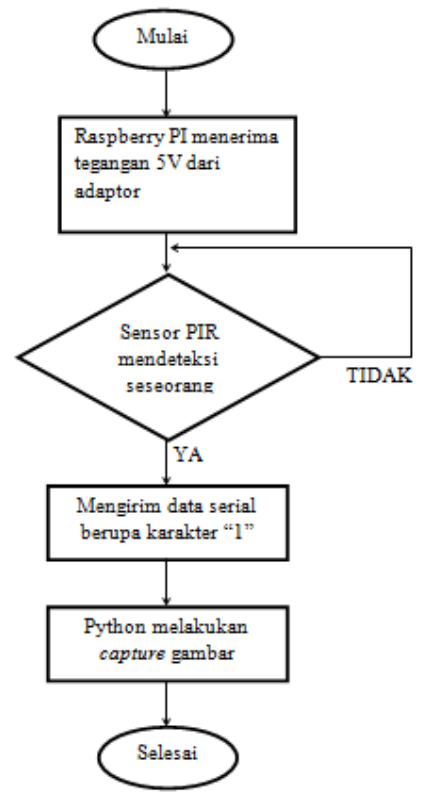

Gambar 5 Flowchart Pembacaan Sensor PIR

Pada gambar 6 merupakan flowchart yang menjelaskan tentang bagaimana alur pembacaan deteksi keberadaan seseorang ketika berada di depan

E-ISSN 2715-6427 
urinoir. Ketika sensor PIR mulai menyala, nilai awal yang dideteksi adalah 0 atau tidak terdapat seseorang. Ketika terdapat gerakan seseorang maka senor PIR memberikan respon yaitu menampilkan nilai digital 1 pada sebuah LCD 1602. Ketika nilai sensor PIR memenuhi nilai yang diharapkan maka software CvAvr mengirim sebuah karakter angka "1" kepada Python untuk melakukan capture secara otomatis.

E. Proses Klasifikasi Status Dehidrasi Dengan Metode JST Peceptron

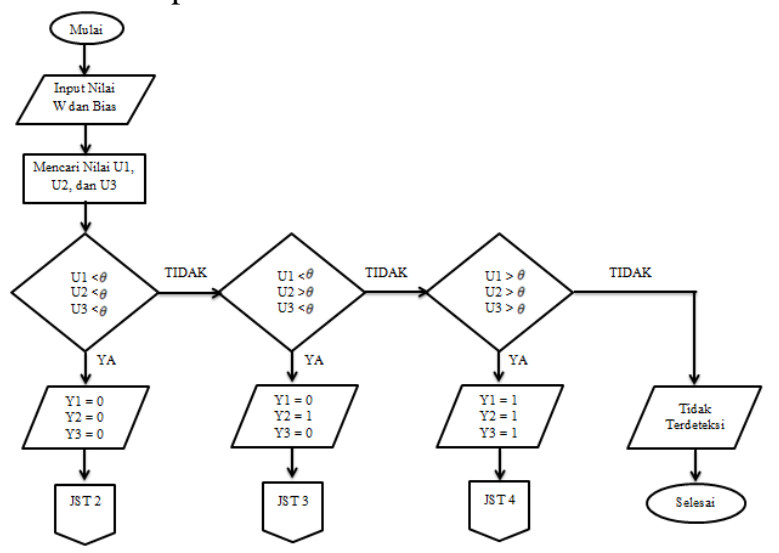

Gambar 6 Flowchart metode JST 1

Pada flowchart 9 dijelaskan alur JST 1 untuk mendapatkan status dehidrasi menggunakan metode jaringan syaraf tiruan perceptron. Setelah mendapatkan nilai $\mathrm{W}$ dan bias dari hasil training data HSV, nilai tersebut dimasukkan dalam program python sehingga dapat dimasukkan ke dalam sebuah rumus metode jst perceptron. Nilai mean HSV yang didapat dari capture oleh kamera Logitech c270 akan diolah menggunakan rumus jst perceptron untuk mencari nilai U1, U2, dan U3. Berikut rumus yang digunakan untuk mencari nilai U1,U2, dan U3

$$
\begin{aligned}
& \mathrm{Y} 1=\left\{\begin{array}{l}
1, U 1 \geq \theta(\text { threshold }) \\
0, U 1 \leq \theta(\text { threshold })
\end{array}\right. \\
& \mathrm{Y} 2=\left\{\begin{array}{l}
1, U 2 \geq \theta(\text { threshold }) \\
0, U 2 \leq \theta(\text { threshold })
\end{array}\right. \\
& \mathrm{Y} 3=\left\{\begin{array}{l}
1, U 2 \geq \theta(\text { threshold }) \\
0, U 2 \leq \theta \text { (threshold })
\end{array}\right.
\end{aligned}
$$

Status dehidrasi ditentukan apabila memenuhi kondisi berikut ini :

$$
\mathrm{Y}=\left\{\begin{aligned}
\text { Tidak Dehidrasi, } \mathrm{Y} 1 & =1 \\
\mathrm{Y} 2 & =1 \\
\mathrm{Y} 3 & =1 \\
\text { Dehidrasi Ringan } \mathrm{Y} 1 & =0 \\
\mathrm{Y} 2 & =1 \\
\mathrm{Y} 3 & =0 \\
\mathrm{Y} 1 & =0 \\
\mathrm{Y} 2 & =0 \\
\mathrm{Y} 3 & =0
\end{aligned}\right.
$$

Jika status dehidrasi sudah diketahui tahap berikutnya yaitu mengklasifikasikan dehidrasi tersebut termasuk tingkat 1 , tingkat 2 atau tingkat 3 dengan proses seperti dibawah ini :

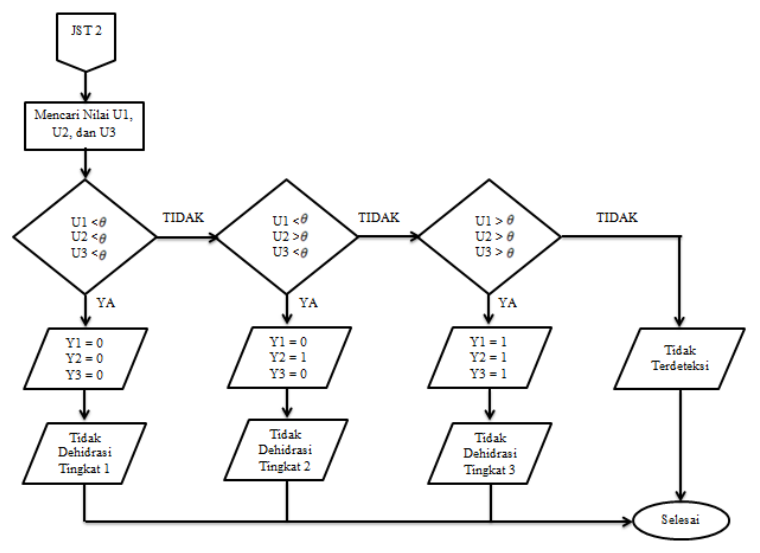

Gambar 7 Flowchart metode JST 2

Pada flowchart .8 dijelaskan bahwa alur JST 2 untuk mengklasifikasikan status tidak dehidrasi tingkat 1, tidak dehidrasi tingkat 2, atau tidak dehidrasi tingkat 3 .

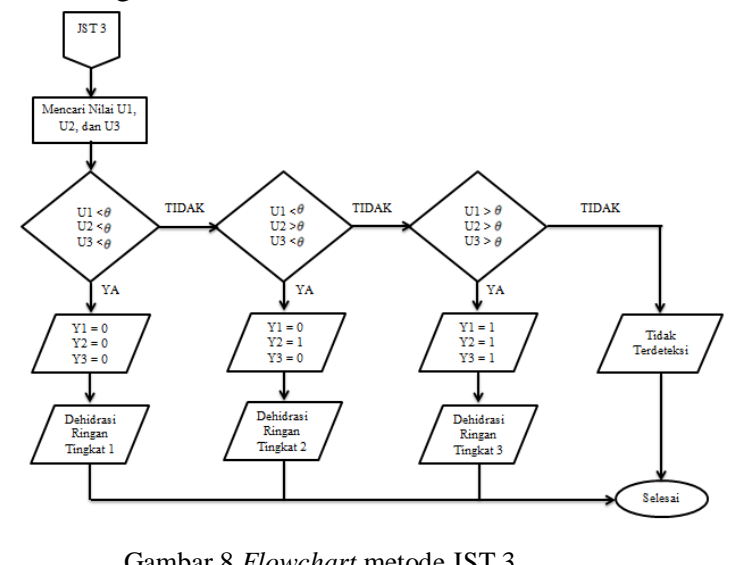

Pada flowchart 9 dijelaskan alur JST 3 untuk mengklasifikasikan status dehidrasi ringan tingkat 1 , dehidrasi ringan tingkat 2 , atau dehidrasi ringan tingkat 3. 


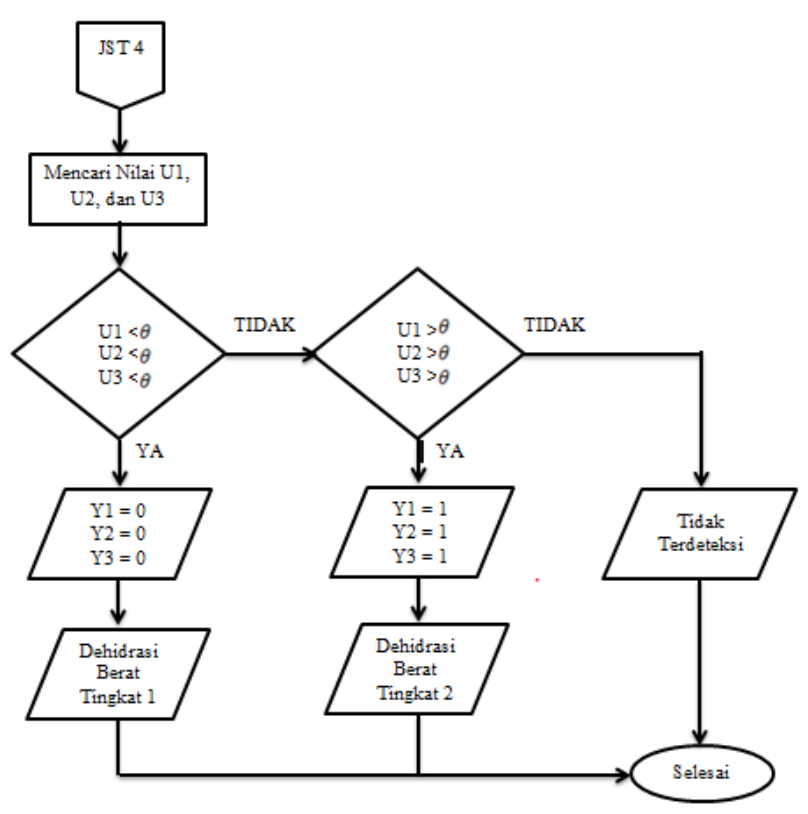

Gambar 9 Flowchart metode JST 4

Pada flowchart 2.10 dijelaskan alur JST 3 untuk mengklasifikasikan status dehidrasi berat tingkat 1, dehidrasi berat tingkat 2, atau dehidrasi berat tingkat 3 .

\section{HASIL DAN PEMBAHASAN}

Percobaan alat untuk pengujian akan dilakukan sebanyak 2 kali yaitu untuk pengujian keberadaan seseorang dan pengujian kasifikasi status dehidrasi. Berikut ini adalah hasil dari setiap percobaan yang telah dilakukan

\section{A. Pengujian Deteksi Keberadaan Seseorang}

Pada pengujian deteksi keberadaan seseorang digunakan sebuah sensor yaitu sensor PIR. Pada pengujian menggunakan sensor PIR yaitu dengan cara menggerakkan bagian badan dengan jarak tertentu. Sensor PIR akan memiliki nilai awal 0 dikarenakan belum mendeteksi gerakan. Jika mendeteksi gerakan maka akan bernilai 1. Berikut hasil percobaan :

Tabel I. Pengujian Sensor PIR

\begin{tabular}{ccc}
\hline Nomor & Jarak & Keterangan \\
\hline 1 & 1 meter & Terdeteksi \\
\hline 2 & 2 meter & Terdeteksi \\
\hline 3 & 3 meter & Terdeteksi \\
\hline 4 & 4 meter & Terdeteksi \\
\hline 5 & 5 meter & Terdeteksi \\
\hline 6 & 6 meter & Tidak Terdeteksi \\
\hline 7 & 7 meter & Tidak Terdeteksi \\
\hline 8 & 8 meter & Tidak Terdeteksi \\
\hline
\end{tabular}

Pengujian sensor PIR dilakukan dengan objek tepat berada di depan urinoir. Pengujian ini dilakukan dengan diawali menggerakan anggota tubuh dengan jarak terjauh yaitu 8 meter, yang

Irfanuddin: Rancang Bangun Smart Urinoir ... selanjutnya objek semakin dekat sehingga dapat diketahui bahwa sensor PIR dapat membaca dengan jarak maksimal 5 meter dari keberadaan sensor PIR.

B. Desain Alat

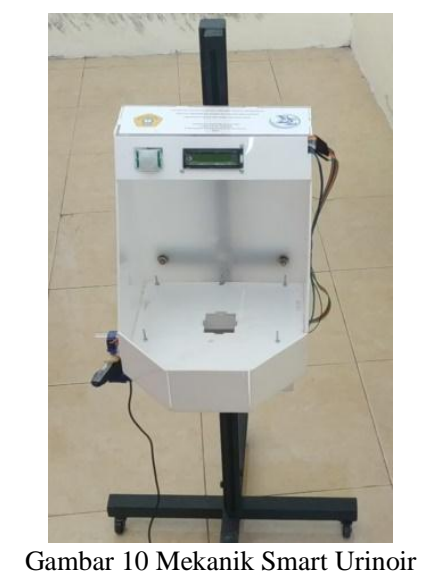

Pembuatan uronoir pada penelitian ini menggunakan bahan berbahan dasar akrilik berwarna putih dengan tinggi keseluruhan $40 \mathrm{~cm}$. Terdapat Kran air dikontrol menggunakan servo untuk menjkdi sistem buka maupun tutup. Smart urinoir ini memiliki sebuah tiang berwarna hitam yang memiliki empat roda. Roda tersebut berfungsi untuk memindahkan urinoir dengan sangat mudah. Dari tampak depan juga terdapat LCD yang berguna untuk menampilkan status dehidrasi. Di samping LCD terdapat sesnsor PIR untuk mendeteksi keberadaan manusia ketika di depan urinoir. Terdapat lubang kecil di tengah bagian bawah yang berfungsi sebagai penghubung pada penampung urin

C. Pengujian Klasifikasi Status Dehidrasi

Pada pengujian ini menggunakan metode jaringan syaraf tiruan yang telah dimasukkan ke dalam sebuah program python. Setelah didapatkan nilai rata - rata $\mathrm{H}, \mathrm{S}$, dan $\mathrm{V}$ selanjutnya dicari nilai $\mathrm{U} 1, \mathrm{U} 2$, dan U3 untuk mendapatkan hasil nilai Y1, Y2, dan Y3. Nilai Y tersebut akan mengklaifikasikan status tingkat dehidrasi pada perhitungan menggunakan JST1. Selanjutnya dilanjutkan status tingkat dehidrasi yang lebih detail. Untuk mengetahui tingkat keberhasilan urinoir ini yaitu dengan membandingkan dengan kertas PURI. Data sampel yang akan diuji yakni berjumlah 60 sampel. Berikut foto sampel urin yang akan diuji :

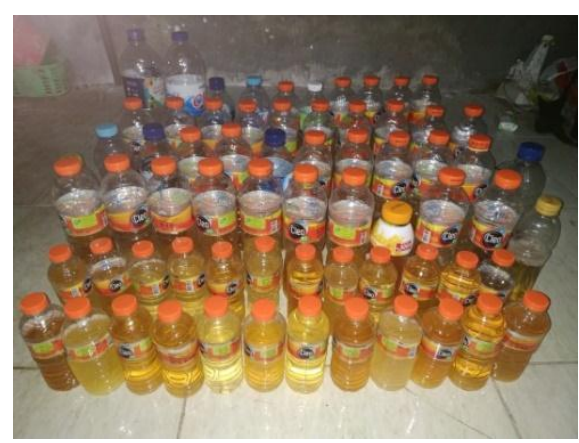

E-ISSN 2715-6427 
JEECOM, Vol. 2, No. 1, April 2020

Gambar 11 Sampel Urin

\begin{tabular}{|l|l|l|l|l|l|l|l|l|l|l|}
\hline No. & Kertas & $\mathrm{H}$ & $\mathrm{S}$ & $\mathrm{V}$ & Jenis & $\mathrm{U} 1$ & $\mathrm{U} 2$ & $\mathrm{U} 3$ & Smart & Ket \\
\hline
\end{tabular}




\begin{tabular}{|c|c|c|c|c|c|c|c|c|c|c|}
\hline & PURI & & & & JST & & & & Urinoir & \\
\hline 1. & TD & 135 & 3 & 52 & JST2 & -27134250 & -1293750 & -27261900 & TD3 & $S$ \\
\hline 2. & TD & 50 & 32 & 60 & JST3 & 6008175 & 9064875 & 6028875 & TD1 & S \\
\hline $3 .$. & DR & 34 & 53 & 61 & JST3 & -28308975 & -1568025 & -28155450 & DR3 & $S$ \\
\hline 4. & DR & 46 & 54 & 62 & JST3 & -25655925 & 936675 & -25559325 & DR2 & $S$ \\
\hline 5. & TD & 120 & 2 & 57 & JST2 & -20465400 & 2061375 & -20499900 & TD2 & $\mathrm{S}$ \\
\hline 6. & TD & 65 & 8 & 58 & JST2 & -1312725 & 8530125 & -1191975 & TD2 & $\mathrm{S}$ \\
\hline 7. & TD & 116 & 12 & 53 & JST2 & -19827150 & 595125 & -19944450 & TD2 & $\mathrm{S}$ \\
\hline 8. & TD & 135 & 3 & 58 & JST2 & -25074600 & 465750 & -25160850 & TD2 & $\mathrm{S}$ \\
\hline 9. & DR & 36 & 66 & 62 & JST3 & -32162625 & -4555725 & -32034975 & DR3 & $\mathrm{S}$ \\
\hline 10. & TD & 120 & 2 & 58 & JST2 & -20122125 & 2354625 & -20149725 & TD2 & S \\
\hline 11. & DR & 53 & 51 & 49 & JST3 & -18279825 & 2220075 & -18303975 & DR2 & $\mathrm{S}$ \\
\hline 12. & DR & 50 & 54 & 51 & JST3 & -20737950 & 903900 & -20737950 & DR2 & S \\
\hline 13. & TD & 51 & 35 & 58 & JST3 & -16956750 & 6865500 & -16880850 & DR2 & TS \\
\hline 14. & TD & 60 & 13 & 58 & JST2 & 696900 & 8745750 & 800400 & TD1 & $\mathrm{S}$ \\
\hline 15. & TD & 140 & 2 & 57 & JST2 & -27158400 & -353625 & -27261900 & TD3 & $\mathrm{S}$ \\
\hline 16. & $\overline{D R}$ & 43 & 65 & 55 & JST3 & -27491325 & -3306825 & -27446475 & $\overline{\text { DR3 }}$ & $S$ \\
\hline 17. & TD & 120 & 3 & 55 & JST2 & -38248425 & -13265250 & -38648625 & TD3 & $\mathrm{S}$ \\
\hline 18. & TD & 105 & 3 & 55 & JST2 & -16064925 & 3208500 & -16068375 & TD2 & $\mathrm{S}$ \\
\hline 19. & TD & 56 & 23 & 51 & JST2 & 305325 & 6399750 & 305325 & TD1 & S \\
\hline 20. & TD & 105 & 3 & 50 & JST2 & -17781300 & 1742250 & -17819250 & TD2 & $\mathrm{S}$ \\
\hline 21. & DB & 28 & 94 & 77 & JST3 & -48313800.0 & -12664950 & -48089550 & DR3 & TS \\
\hline 22. & DR & 40 & 65 & 60 & JST3 & -30052950.0 & -3556950.0 & -29958075 & DR3 & $\mathrm{S}$ \\
\hline 23. & DR & 41 & 55 & 65 & JST3 & -28388325.0 & -201825.0 & -28246875 & DR3 & $\mathrm{S}$ \\
\hline 24. & DR & 52 & 42 & 61 & JST3 & -19906500.0 & 5447550.0 & -19827150 & DR2 & $\mathrm{S}$ \\
\hline 25. & $\overline{D R}$ & 51 & 40 & 61 & JST3 & -19558050.0 & 5764950.0 & -19470075 & $\overline{\text { DR2 }}$ & $S$ \\
\hline 26. & TD & 50 & 29 & 56 & JST3 & 4433250.0 & 8124750.0 & 4447050 & TD1 & $\mathrm{S}$ \\
\hline 27. & TD & 96 & 3 & 58 & JST2 & -12023250.0 & 5175000.0 & -11974950 & TD2 & $S$ \\
\hline 28. & TD & 54 & 14 & 57 & JST2 & -1003950.0 & 6166875.0 & -962550.0 & TD2 & $\mathrm{S}$ \\
\hline 29. & TD & 60 & 17 & 54 & JST2 & -407100.0 & 7262250.0 & -358800.0 & TD2 & $\mathrm{S}$ \\
\hline 30. & TD & 50 & 39 & 49 & JST3 & -15361125.0 & 4797225.0 & -15349050 & DR2 & TS \\
\hline
\end{tabular}

Tabel II. Pengujian Klasifikasi Status Dehidrasi 
Pada pengujian smart urinoir dengan menggunakan 60 sampel urin didapatkan 41 data memiliki status tidak dehidrasi, 15 data memiliki status dehidrasi ringan, 1 memiliki status dehidrasi berat, dan 3 data salah deteksi. Data yang tidak terdeteksi tersebut dikarenakan nilai Y1, Y2, dan Y3 tidak termasuk dalam klasifikasi status dehidrasi yang telah ditentukan sebelumnya. Sebelum di ukur menggunakan smart urinoir, sampel urin dicocokan pada sebuah kertas PURI yang dimana terdapat klasifikasi dehidrasi berdasarkan warna. Dari 60 sampel yang diuji, 57 diantaranya memiliki status dehidrasi yang sama antara hasil smarturinoir dengan kertas PURI. Jadi dapat dikatakan tingkat keberhasilan yaitu 95 persen.

\section{KESIMPULAN}

Berdasarkan desain mekanik alat, desain sistem, dan pengujian dari sistem yang telah dilakukan maka berikut ini adalah kesimpulan yang diperoleh :

1. Pembacaan sensor PIR memiliki jangkauan dengan panjang maksimal 5 meter antara sensor dengan objek yang bergerak. Jika objek berada diluar jangkauan tersebut maka sensor tidak dapat terdeteksi

2. Dari 60 sampel yang diuji, 57 diantaranya memiliki status dehidrasi yang sama antara hasil smart urinoir dengan kertas PURI. Jadi hasil pengujian menggunakan smart urinoir memiliki tingkat keberhasilan 95 persen

3. Dengan menggunakan metode JST perceptron, pengujian smart urinoir dengan menggunakan 60 sampel urin didapatkan 41 data memiliki status tidak dehidrasi, 15 data memiliki status dehidrasi ringan, 1 memiliki status dehidrasi berat, dan 3 tidak sesuai. Data yang tidak terdeteksi tersebut dikarenakan nilai Y1, Y2, dan Y3 tidak termasuk dalam klasifikasi status dehidrasi yang telah ditentukan sebelumnya.

\section{DAFTAR PUSTAKA}

[1] M. Horne, Mimma \& Pamela L. Swearingen. 1993. Keseimbangan Cairan Elektrolit dan Asam Basa. Jakarta : Buku Kedokteran EGC

[2] R. Z. Amani, R. Maulana, D. Syauqy ( 2017 ). Sistem Pendeteksi Dehidrasi Berdasarkan Warna dan Kadar Amonia pada Urin Berbasis Sensor TCS3200 Dan MQ135 dengan Metode Naive Bayes. Jurnal Pengembangan Teknologi Informasi Dan Ilmu Komputer. Universitas Brawijaya

[3] Y. N. S. Ulvie, H. S. Kusuma, R. Agusty ( 2017 ). Identifikasi Tingkat Konsumsi Air dan Status Dehidrasi Atlet Pencak Silat Tapak Suci Putra

Irfanuddin: Rancang Bangun Smart Urinoir ...
Muhammadiyah Semarang. Jurnal Media Ilmu Keolahragaan Indonesia. Universitas Muhamadiyah Semarang

[4] Adela, V. Identifikasi Diabetes Melalui Bau Urine Dengan Sensor Gas Menggunakan Metoda Pembelajaran Multilayer Percetron. Jurusan Elektronika, Politeknik Negri Padang.

[5] Merita, Aisah, Siti Aulia ( 2018 ). Status Gizi Dan Aktivitas Fisik Dengan Status Hidrasi Pada Remaja Di Sma Negeri 5 Kota Jambi. Jurnal Ilmu Kesehatan Masyarakat. STIKES Baiturrahim Jambi.

[6] Mukhti, I.N.P. Sistem Otomasi Dalam Penyortiran Tomat Dengan Image Processing Menggunakan Metode Deteksi Rgb. Universitas Telkom

[7] Latif Nasyarudin ( 2016 ). Pengembangan Alat Deteksi Tingkat Dehidrasi Berdasarkan Warna Urine Menggunakan LED dan Fotodioda. Universitas Islam Negeri Sunan Kalijaga.

[8] Pertiwi Donna ( 2015 ). Status Dehidrasi Jangka Pendek Berdasarkan Hasil Pengukuran PURI ( Periksa Urin Sendiri ) Menggunakan Grafik Warna Urin pada Remaja Kelas 1 dan 2 di SMAN 63 Jakarta. Universitas Islam Negeri Syarif Hidayatullah.

[9] Halis Isman (2017). Rancang Bangun Sistem Informasi Kondisi Dehidrasi Tubuh Melalui Warna Urin (Smart Toilet). Universitas Islam Negeri Maulana Malik Ibrahim Malang

[10] Taufiqurrohman Harqi (2017). Pengembangan Urinoir Sebagai Pendeteksi Status Hidrasi Berbasis Arduino Uno Dan Sensor Warna. Institut Pertanian Bogor.

[11] Prabowo dan Pranata. 2014. Buku Ajar Asuhan Keperawatan Sistem Perkemihan ( edisi ke 1 ). Yogyakarta : Nuha Medika.

[12] Syaifuddin. 2007. Fisiologi Tubuh Manusia Untuk Mahasiswa Keperawatan Edisi 2. Jakarta : Salemba Medika.

[13] Putra, D.I. 2018. Rancang Bangun Pendeteksi Diabetes Melitus Dengan Menggunakan Backpropagation. Universitas Trunojoyo Madura. 